\title{
Knowing me, Knowing you: personality and peer appraisal
}

\section{INTRODUCTION}

Since the inception of the national system in 2002, the Scottish GP appraisal process has been underpinned by educational principles of reflection on current practice, evidence of learning and its implementation in daily practice to improve patient care. To encourage reflection and learning by appraisees in Scotland, GP appraiser training is evolving to improve the skills of appraisers. ${ }^{1}$ The aim is to encourage appraisee reflection and learning by providing appropriate personal and professional challenges and constructive feedback in preparation for enhanced appraisal for revalidation.

While most appraisals end in positive outcomes, evaluation using the GP Scot $3 a$ (appraisee) and $3 b$ (appraiser) electronic feedback database sometimes indicates a difference between the two peers' impression of the appraisal interview. Could this disparity be attributed to unknown differences in personality and doctors' communication styles?

Since 2008, facilitated workshops have identified variation across four key domains of the appraisal process: appointments, paperwork, interviewing and feedback, where personality was perceived to result in particular behaviours. Formal awareness-raising of personality issues may therefore add value to appraisal training.

The Myers-Briggs type indicator $\left(\mathrm{MBTI}^{\circledR}\right)$ is a psychometric test used world-wide. ${ }^{2}$ Developed by Katharine Briggs and Isabel Myers from theories developed by Carl Jung in the 1900s, MBTI has been extensively tested for reliability and validity. The Scottish GP appraisal scheme has developed workshops on MBTI training to increase appraisers' awareness of their personal styles and preferences. Key objectives are to enable appraisers to understand and value others by first appreciating the importance of understanding themselves. Further, where differences arise, appraisers are encouraged to adapt to meet their colleagues' needs in order to establish rapport and ensure that the appraisal maximises the potential for reflection, the collection of evidence, and construction of a personal development plan.

\section{PERSONALITY TYPES}

The MBTI is a questionnaire, which assesses eight preferences derived from four dimensions (Box 1). 'Extraversion' (E) and 'Introversion' (I) refers to the source of individuals' energy. An 'Extravert' typically derives energy from interacting with others prefering to talk problems and issues through. They are viewed as sociable and expressive. Conversely, an 'Introvert' is energised 'from within'. They prefer to take time to think and reflect on problems and are often considered by others to be private and contained.

The dimension 'Sensing' (S) and 'iNtuition' (N) focuses on how we take in information. People with a preference for 'Sensing' will take in information using the five senses; for example, what they see, hear, smell, touch and taste. Those with a preference for 'iNtuition', pay attention to what might be described as the sixth sense - the unseen world of meanings, inferences, hunches, insights, and connections.

Preference for 'Thinking' $(T)$ and 'Feeling'(F) relate to how we make decisions. 'Thinkers' use logic to analyse a

Box 1. Four dimensions. situation to achieve an objective, reasoned and fair outcome. They may be considered 'hard headed'. People with more 'Feeling' characteristics, however, strive to understand others, value relationships and harmony, and assess a situation by its impact on people. They may be referred to as 'tender hearted'.

The 'Judging'-'Perceiving' J-P couplet explains the individual's orientation to time. 'Judging' types prefer to be organised and scheduled, feeling energised, when decisions are made. 'Perceiving' individuals are more casual and openended preferring to live life spontaneously and often subject to change. They may be perceived by others as eternal procrastinators. To 'Perceivers', time does not matter.

\section{APPOINTMENTS}

An appraiser with a preference for 'Judging' may find an appraisee with a preference for 'Perceiving' very stressful, unable to pin down the appraisee to a date for an interview and transfer of paperwork. What the 'Judging' appraiser may not appreciate is that 'Perceivers' are energised by last minute pressure. A 'Perceiving' appraisee on the other hand may feel oppressed by the 'Judging' appraiser's need to have the task completed ahead of schedule.

\section{PAPERWORK}

Appraisees who prefer 'Sensing' like facts and figures, or 'concrete reality'. 'Sensing' skills are therefore useful for the completion of appraisal paperwork. A 'Sensing' approach enables specific information data to be collected and explored from practical application and experiential learning.

Appraisers who are 'Sensing' types may find appraisees with a preference for 'Intuition' vague, impractical, and unrealistic with evidence lacking in their paperwork. That is not to say the information does not exist. It may be restricted to thoughts and ideas, which are 
meaningful and arise intuitively, but are not committed to paper. However, appraisers who prefer 'Sensing' may be perceived by their opposites as 'nitpicking' and unimaginative which can lead to communication difficulties.

\section{INTERVIEW}

Appraisees who prefer 'Introversion' will be naturally reflective people, who may concentrate on limited material, such as a complaint. Appraisers with a preference for 'Extraversion' are more likely to talk rapidly, loudly and interrupt, not realising the importance of silence during deliberate pauses in the discussion.

In contrast, appraisees who prefer 'Extraversion' verbalise thoughts as they are forming in their minds. Appraisers who have a preference for 'Introversion' may experience problems assimilating a structured report in the face of an uncontrolled verbal 'flow' of information from this type of appraisee.

\section{FEEDBACK}

The GP Scot $3 a$ (appraisee) and $3 b$ (appraiser) electronic feedback system includes questions such as 'Were you able to establish a good rapport with your appraisee?', 'How sensitive was your appraiser?', and 'Overall, how did you feel by the end of the appraisal interview?' that is, how the appraisee 'feels'. This emphasises the Thinking-Feeling axis.

Appraisers who prefer 'Thinking' may appear to be testing the appraisee or their knowledge and weighing up their evidence. For 'Thinker's', challenge can be considered desirable and stimulating.

Appraisers whose type is more 'Feeling' orientated are more likely to focus on their impact on people, their actions and how situations can be resolved. They are more caring about feelings and avoid confrontation at all costs.

At the end of an appraisal interview appraisees with a preference for 'Thinking' may seek recogition for a job 'well done' whereas appraisees, whose type is
'Feeling' may prefer to be appreciated and have their personal contribution acknowledged. Feedback, crucial for quality assurance of appraisal, may provide insight into the extent to which personality differences have arisen and been managed in the interview.

\section{WHAT MBTI CAN ADD TO APPRAISAL}

Understanding Personality Types using MBTI can be a key to understanding how appraisees prefer to be communicated with and understood in a professional situation, such as peer appraisal. Being aware of the impact of personality preferences enables the appraiser to prepare for the process and consciously make choices to adapt their style to suit the appraisee.

Sensing-Intuition and Thinking-Feeling are key dimensions in combination and it is important that as the appraiser, regardless of personal preferences, all four couplets are considered (Box 2). So it is important not only to consider the facts and data (Sensing), but to consider and discuss connections and linkages with other aspects of the appraisees work and how they might develop concepts further (Intuition). The Thinking-Feeling dimension requires the appraiser to question and discuss the logic of decisions, as well as tap into what reactions and feelings the appraisee had to specific events, outcomes and research.

Like the appraisal process itself, there is no 'pass or fail'/ 'right or wrong' response just as there is no 'better or worse' Personality Type. All Types and preferences are important and valuable, and all practices can benefit from having a diversity of styles.

\section{DISCUSSION}

An awareness of Personality Type is helpful in improving appraisers understanding of their own preferences and how others prefer to communicate or assimilate information. Shifting the focus from

\section{Box 2. Adapting to appraisees' preference (ST, SF, NT, NF).}

\section{Sensing/Thinking - Facts with Practicality} Present facts with brevity and clarity

Avoid vagueness and ambiguity

Be direct and honest

Offer options for consideration

Provide factual written information

Support arguments with evidence or comparable data

Expect intense questions, which may be testing

Intuition/Thinking - Logical with Competence

Value intelligence and interpretations

Demonstrate competence and knowledge

Be open, explicit and do not conceal anything Consider alternative approaches and models

Offer options to explore patterns, trends and links Avoid seeking a personal relationship, at least until you have 'proved' your worth

Listen and understand before offering advice
Sensing/Feeling - Personal Services

Be warm and amiable

Listen attentively and patiently

Focus on the individual and acknowledge their work

Share helpful information and appropriate examples

Give feedback on similar scenarios

Clarify what alternatives/opportunities exist, allow time and don't dictate

\section{Intuition/Feeling - Support Their Vision}

Respect individuality and personal contributions

Empathise with opinions, feelings and aspirations

Provide general advice without being specific

Balance an analytical approach with compassionate concern

Acknowledge that personal situations are unique and don't generalise

Be honest and genuine

Seek to establish a personal relationship 
neglecting to valuing differences in personality can benefit interactions and generate more options and possibilities. Applying these principles to an appraisal process involves adapting to meet the appraisees' individual needs. Personality Type training should therefore assist in generating richer discussions, higher levels of interest in immediate and future outcomes, and energise the process for all parties.

\section{CONCLUSION}

Peer appraisal is perceived to be the 'cement', which binds the system for the revalidation of doctors, who wish to be licensed to practice in the UK. Appraisers need to acquire the requisite skills to ensure that doctors engage fully and honestly in the appraisal and revalidation processes. In order to fulfil this requirement, training to enable an understanding of personality and how it influences the outcome of appraisal is essential for peer appraisal.

\section{Jill Murie}

\section{Acknowledgements}

The author wishes to thank Georgia Barr Consulting Ltd for facilitating GP appraiser training in NHS Lanarkshire and the Scottish GP National Appraiser conference and Diane Kelly, Assistant Director, NHS Education for Scotland for advice and support.

\section{REFERENCES}

1. Law S, Haman H, Cameron N, Staples I. GP peer appraisal in Scotland: an ongoing and developing exercise in quality. Education for Primary Care 2009; 20: 99-103.

2. Myers IB, McCaullet MH, Quenk NL, Hammer AL. Manual: a guide to the development and use of the Myers-Briggs type indicator. 3rd edn. Palo Alto, CA: Consulting Psychologists Press, 1998.

DOI: 10.3399/bjgp10X502001

\section{There's no such thing as flexible training for GP trainees}

It was my own fault for falling in love with a fellow medical student and marrying her 2 days after we graduated. Apart from never doing nights at the same time, our first Foundation Year worked out rather well. Then there was the small matter of the arrival of a new baby in Foundation Year 2.

Becky returned to work full-time as a Foundation Year 2 doctor while I was an StR1 on a GP vocational training scheme. As a result of busy jobs with long hours our daughter spent more of her waking hours in nursery than with us. We would swap our on-calls to make sure they didn't clash and so someone was free to collect her from nursery.

We therefore decided that I would work less than full-time (LTFT) and look after our daughter, with the help of our extended family. Becky was keen to get through her hospital jobs speedily to train as a GP as well.

Any notion I had about the flexibility of LTFT training soon disappeared. Every 8 months I changed jobs and worked on different days of the week in different placements. Furthermore, I would usually swap the days of the week I worked half way through the post, to make sure I wasn't missing out on learning opportunities. It is impossible to chop and change the days your child spends at a popular nursery.

So for the last year or so we've used a mixture of nursery and help from extended family to provide care for our daughter. Paying for nursery 5 days a week to keep our options open for changing working days of the week was not an attractive option when my salary had been chopped.

Choosing to work as an LTFT trainee is one of the best career decisions I have made. It's given me the opportunity to see more of my children as they grow up and to not merely survive, but thrive and learn in my hospital posts. However, one thing I have realised is that in my experience, LTFT is certainly not flexible.

'Nobody on his deathbed ever said, "I wish I had spent more time at the office".' Senator Paul Tsongas (1941-1997)

\section{Samir Dawlatly}

DOI: 10.3399/bjgp10X502010 